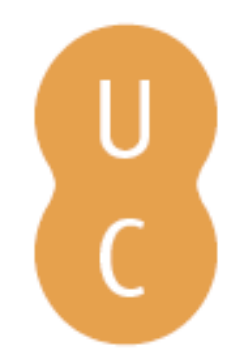

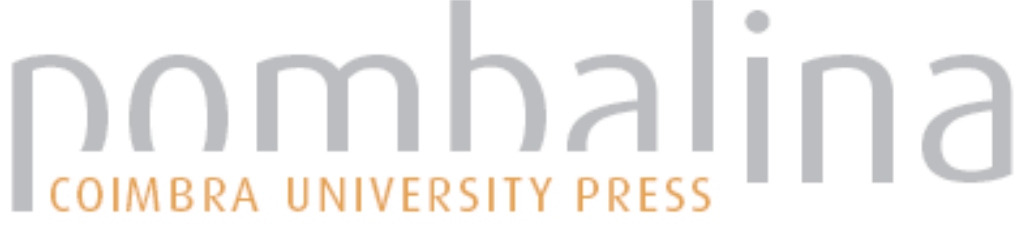

\section{Estudos organizacionais: da análise à síntese}

Autor(es): $\quad$ Cunha, Miguel Pinha e; Cunha, João Vieira da

Publicado por: Imprensa da Universidade de Coimbra

URL

persistente:

URI:http://hdl.handle.net/10316.2/32731

DOI:

DOI:http://dx.doi.org/10.14195/978-989-26-0452-7_6

Accessed : $\quad$ 26-Apr-2023 13:01:26

A navegação consulta e descarregamento dos títulos inseridos nas Bibliotecas Digitais UC Digitalis, UC Pombalina e UC Impactum, pressupõem a aceitação plena e sem reservas dos Termos e Condições de Uso destas Bibliotecas Digitais, disponíveis em https://digitalis.uc.pt/pt-pt/termos.

Conforme exposto nos referidos Termos e Condições de Uso, o descarregamento de títulos de acesso restrito requer uma licença válida de autorização devendo o utilizador aceder ao(s) documento(s) a partir de um endereço de IP da instituição detentora da supramencionada licença.

Ao utilizador é apenas permitido o descarregamento para uso pessoal, pelo que o emprego do(s) título(s) descarregado(s) para outro fim, designadamente comercial, carece de autorização do respetivo autor ou editor da obra.

Na medida em que todas as obras da UC Digitalis se encontram protegidas pelo Código do Direito de Autor e Direitos Conexos e demais legislação aplicável, toda a cópia, parcial ou total, deste documento, nos casos em que é legalmente admitida, deverá conter ou fazer-se acompanhar por este aviso.

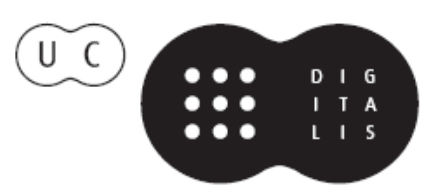




\section{A. DUARTE GOMES - ANTÓNIO CAETANO JOSÉ KEATING • MIGUEL PINA E CUNHA

\author{
Coordenadores
}

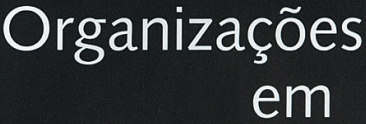

Transição

Contributo da Psicologia do Trabalho

e das Organizaçōes 
(Página deixada propositadamente em branco) 


\section{A. DUARTE GOMES - JOSÉ KEATING ANTÓNIO CAETANO - MIGUEL PINA E CUNHA Coordenadores}

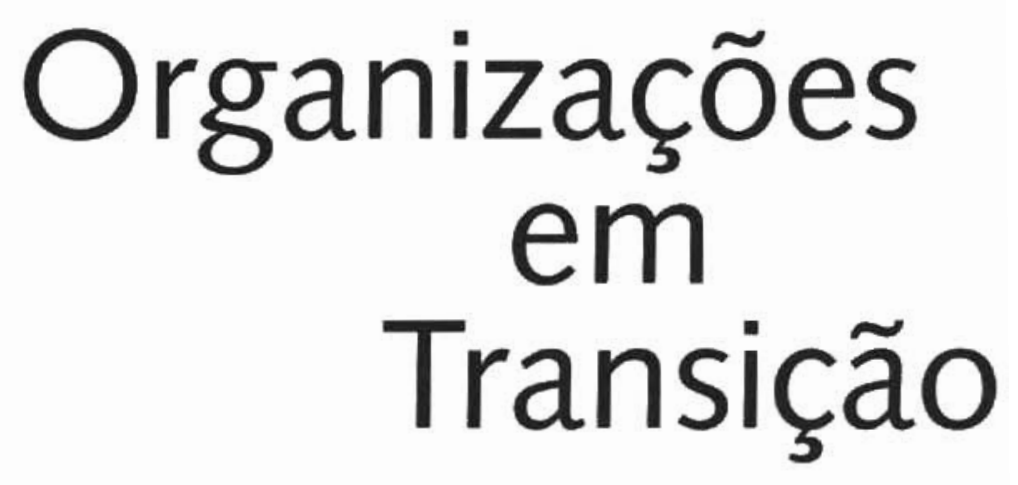

Contributos da Psicologia do Trabalho e das Organizações 


\section{COORDENACÁO EDITORIAL \\ Imprensa da Universidade de Coimbra \\ CONCEPÇÃO GRAFACA \\ António Barros \\ EXECUÇÃO GRAFICA \\ G.C. - Gráfica de Coimbra, Lda. \\ Palheira - Assafarge - Apart. 3068 \\ 3001-453 Coimbra Codex}

ISBN

972-98225-3-0

DEPOSITO LEGAL.

153435/00

(c) JunHo 2000. Imprensa da Universidade de Coimbra 


\title{
ESTUDOS ORGANIZACIONAIS: DA ANÁLISE À SÍNTESE
}

\author{
Miguel pina e Cunha, joão Vieira da Cunha \\ FACULDADE DE ECONOMIA DA UNIVERSIDADE NOVA DE LISBOA
}

\section{INTRODUÇÃO}

Praticamente tudo o que hoje é escrito sobre gestão tem um tema comum: o que funcionou durante muito tempo já não funciona mais, há que fazer as coisas de uma forma diferente. Gerir, fazer as coisas bem, resulta, nas envolventes turbulentas em que vivemos, em fabricar um produto que foi ultrapassado pelas inovações sucessivas desenvolvidas pelos apóstolos da eficácia. Organizações e líderes vivem e apregoam a inovação constante. Jack Welch, Richard Branson e Ricardo Semler são heróis comuns a páginas e páginas escritas pelos ditos 'gurus' da gestão (Micklethwait e Wooldridge, 1996) devido ao seu apelo à destruição da rotina, e à mudança constante, nem que seja só por mudar (e.g. Peters, 1987).

Esta nova corrente é apelativa. A mudança está na moda. Uma moda promovida quer pelos seus criadores (os gurus) quer pelas maisons (as consultoras), que a fabricam, promovem e vendem (Abrahamson, 1991). Tem havido poucas atitudes saudáveis em relação a este fenómeno. Alguns, devido às inúmeras pressões que sobre eles recaem, acabam por sucumbir a um situação em que, na tentativa de agradar a todos os stakeholders, 'vestem' a forma organizacional 'da moda' e lidam com um número crescente de problemas e oportunidades; a organização pode cair, assim, numa situação que ameace os seus resultados e, em última análise, a sua sobrevivência. Outros desconfiam. Argumentam que as novas teorias de gestão são pouco mais do que isso, 
teorias, modas. Preferem continuar a vestir as suas organizações com o fato escuro e a gravata discreta que lhes têm trazido resultados. Resultados aceitáveis, nem bons nem maus. Aqueles que povoam os níveis inferiores deste tipo de organizações clamam pela mudança (Peters, 1992) e muitas vezes suspiram com visōes do seu chefe a ler um livro de Tom Peters. A 'Senda da Excelência' (Peters e Waterman, 1982) já chega. 'Em busca do uau!' já é sonhar muito alto.

Nenhuma destas atitudes parece sustentável a longo prazo. Da primeira podem resultar, de facto, produtos inovadores. Mas este tipo de organizações muitas vezes tem o produto com que todos sonham, a um preço que ninguém pode (ou quer) pagar. A segunda normalmente resulta numa organização que produz de forma cada vez mais barata um produto que já ninguém quer.

Neste sentido, há uma interrogação aparentemente importante em cuja resposta reside a relevância do trabalho de quem estuda gestão para $\circ$ de quem a pratica: o que é que os gestores devem fazer? A figura I apresenta algumas alternativas.

Teoria 'Tradicional'

(e. g.Taylor)
Teoria 'Moderna'

(e. g. Peters)

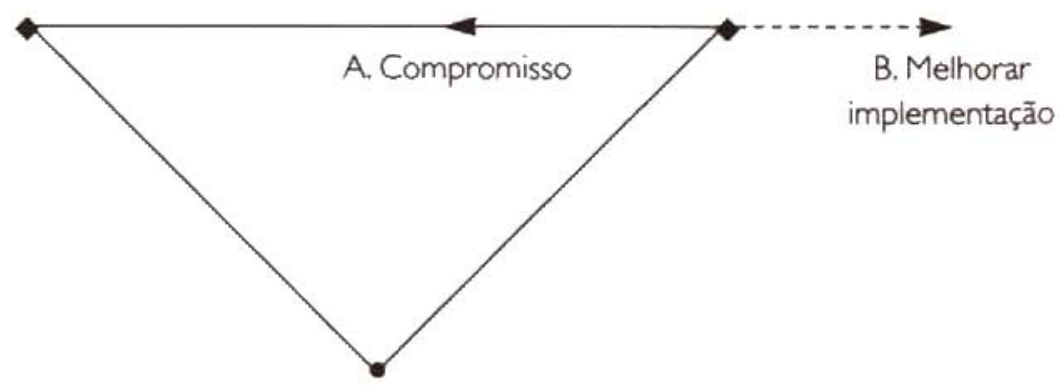

C. Teoria 'Dialéctica'

[Complexidade]

(e. g. Stacey)

FGGURA 1 - Onde procurar soluçōes aos dilemas da gestão? 
Uma primeira resposta estaria relacionada com a necessidade da aplicação correcta das técnicas inerentes às novas teorias de gestão. Alguns dos seus autores afirmam que é na implementação, e não na teoria em si, que residem os fracassos (e.g. Senge, 1990). Haveria por isso que melhorar a competência dos gestores na aplicação deste tipo de técnicas. Livros como 'Managing for Dummies' (Nelson e Economy, 1996) são tentativas neste sentido. Curiosamente os autores dedicam o livro a "qualquer gestor que tenha tentado fazer o seu trabalho e a todos os empregados que tiveram que viver com as consequências" (Nelson e Economy, 1996: xi).

Outra resposta, a do senso comum, aconselharia aqui alguma moderação: 'no meio está a virtude'. O meio, no entanto, é um lugar perigoso em qualquer mercado (Porter, 1998). Felizmente, a ciência organizacional é mais do que senso comum. De facto, podemos encontrar na própria evolução recente da teoria das organizações, uma alternativa de resposta para esta questão.

Qualquer manual de comportamento organizacional contém um capitulo sobre a evolução histórica da ciência organizacional. Essa evolução tem vindo a seguir um percurso que começou por configurações em que imperavam a formalidade e o controlo externo (Taylor, 1911 ) e têm vindo a evoluir para configuraçōes mais informais em que predominam o controlo interno ou auto-controlo (Peters, 1992). Se neste momento quer o primeiro quer o segundo tipo de organizações não parece adequado, surge, na continuação da interrogação formulada anteriormente, a pergunta seguinte: para onde vai a teoria organizacional? Para maiores níveis de informalidade? Ou vai voltar para modelos mais formais, recuando historicamente?

\section{DIALECTICA: UMA NOVA PERSPECTIVA(1)}

Curiosamente a resposta a esta questão já pode ser dada. A teoria da complexidade, ao recorrer a regras muito apertadas que permitem o aparecimento de variedade via criatividade (que acontece por causo dessas regras e não apesar delas), faz uma síntese entre vários pares extremos, considerados como tese e antítese uns dos outros (e.g. integração e diferenciação, controlo

(1) Esta secção retoma, com pontuais actualizações, um argumento desenvolvido noutro local (Cunha e Cunha, 2000). 
e autonomia). Esta visão dialéctica da teoria da organização e da prática da gestão permite chegar a um modelo mais próximo daquilo que tem vindo a ser descrito como a realidade da gestão, mas que mantém algum poder normativo. Utilizar um modelo dialéctico significa assim procurar um novo estado. neste caso uma nova corrente, através do confronto entre os dois pólos de um paradoxo (Poole e Van de Ven, 1989). Em vez de escolher entre centralização e descentralização, chegar a um meio termo entre eficácia e eficiência e procurar um compromisso entre autonomia e controlo, o que argumentamos é que é possível que cada uma destas dialécticas exista em simultaneo na organização - aumentando também a sua capacidade de prosperar em envolventes de alta velocidade (e.g. Brown \& Eisenhardt, 1998). Alguns autores, mesmo até no campo normativo, já fizeram um esforço neste sentido (e.g. Peters, 1987). No entanto, a simultaneidade de duas forças contraditórias é meramente um artifício semântico. De facto, quando interrogado sobre qual seria a lição que gostava de legar à Humanidade, Peters refere o seguinte paradoxo: 'o sucesso resulta de relações estreitas, mas as relações estreitas destroem a capacidade de adaptação [garantia de insucesso, mesmo a curto prazo, nas envolventes turbulentas de hoje (Peters, 1992)]' (Peters, 1995: 41). Por outras palavras, Peters afirma que o sucesso resulta do aumento da eficiência, mas que esse aumento leva a uma redução na capacidade de procurar a eficácia o que, num ambiente de mudança, leva rapidamente ao insucesso. Contudo, se abordarmos este paradoxo de uma forma dialéctica, a síntese resultante da justaposição de tese (eficácia) e antítese (eficiência) resulta naquele que é sentido como um dos principais desafios da gestão de hoje ser tão competente na exploração por investigação (detectar problemas e descobrir oportunidades) como na exploração por utilização (resolver problemas e aproveitar oportunidades).

Este desafio abarca assim dois tipos de problemas: ( 1 ) problemas de eficácia, que se reportam a questões ligadas à estratégia ("qual é a coisa certa a 124 fazer?') e (2) problemas de eficiência, que têm a ver com questões ligadas à organização ('como fazer as coisas bem?'). Consequentemente, ao alargar este exercício de dialéctica a um conjunto mais amplo de áreas da gestão e das organizações, fá-lo-emos classificado-as como relacionadas com a estratégia ou com a organização, tendo em conta que estas duas áreas - que além de serem as mais críticas para quem exerce a gestão no seu quotidiano - aparecem muitas vezes emparelhadas, quando se fala de teoria das organizações 
(Mintzberg, 1995; Quinn, 1995; Weick, 1979). O nosso objectivo é, assim. tendo esta categorização como referência, o de fazer emergir um modelo que, apesar de resultar do confronto entre a teoria dita 'tradicional' e a 'moderna', esteja mais próximo dos desafios centrais da gestão de organizações nos nossos dias, do que as duas correntes que the servem de input.

\section{ESTRATEGIA}

\section{TESE (AI): NAS ORGANIZAÇÕES DO FUTURO OS TRABALHADORES PLANEARÃO E EXECUTARĀo}

Todas as teorias que se incluem na corrente dita moderna apelam a um elevado grau de participação dos trabalhadores no processo de planeamento. Tomando como ponto de partida a definição de planeamento estratégico de Harrison (1987) (estratégia como resposta às perguntas: o que vender, como produzir/vender e onde vender), podemos ver que este argumento assenta em duas proposições: em primeiro lugar. ( 1 ) apenas as pessoas mais próximas da acção/mercado possuem a informação necessária para responder às perguntas 'o que vender?' e 'onde vender?'; em segundo lugar (2) apenas as pessoas mais familiarizadas com a tecnologia e com o produto possuem a informação adequada para responder à pergunta 'como produzir/vender?' Estas proposições são resultantes de quatro condicionantes. Em primeiro lugar (a) ter uma elevada dose de responsabilidade no processo de planeamento confere ao trabalhador uma percepção de autonomia que tem efeitos motivadores não negligenciáveis (Hackman e Oldham, 1980). Depois (b) o conhecimento explícito ou articulável que os trabalhadores possuem deve ser utilizado por eles próprios como input para o planeamento, já que fazê-lo chegar aos níveis organizacionais a quem é normalmente atribuído o papel de decisor levaria muito tempo - um problema em envolventes de alta velocidade (Stalk, 1988). Além disso, (c) os enviesamentos típicos da comunicação vertical nas organizações (Handy, 1976) distorceriam a informação antes desta chegar ao topo. Por último, (d) existe uma parte importante do conhecimento utilizado pelos trabalhadores no processo de planeamento que é tácito (Nonaka, 1991) e por isso não articulável nem transmissivel. Por tudo isto, esta abordagem defende que devem ser os trabalhadores a planear a sua própria acção, e a executá-la posteriormente (Byham e Cox, 1998). 
ANTITESE (AI): NAS ORGANIZAÇÕES DE SUCESSO OS GESTORES PLANEIAM

O princípio da separação entre planeamento e execução foi um dos grandes avanços científicos na gestão do início do século. De acordo com Taylor (1911), o fundador desta corrente, apenas as pessoas com capacidade e conhecimento para aplicar o método científico ao trabalho (neste caso, operário) são suficientemente competentes e suficientemente distantes do processo produtivo para não serem contaminados pelo conhecimento tácito ( $\mathrm{e}$, na perspectiva deste autor, imperfeito) que aí abunda. Só através da 'gestão científica do trabalho' é possível conceber o melhor processo produtivo para a organização em causa (responder à pergunta 'como produzir/vender?'). A segunda onda racionalista na área da gestão veio enriquecer esta corrente com instrumentos de análise da envolvente externa, tornando-a equipada para viver num mundo sistémico, aberto e em mudança (Robbins, 1990). Deste modo, aquilo que podemos chamar a 'avaliação científica da envolvente', passou a permitir a esta corrente responder às perguntas 'onde vender?' e 'o que vender?', através dos modelos de portfolio e da 'Industrial Organization' (Pettigrew e Whipp, 1993; Porter, 1998; Andrews, 1995). A motivação dos trabalhadores, assente no paradigma do 'homo economicus', era aqui assegurada pelo incremento dos salários (Taylor, 1911). Em envolventes em rápida mudança e de grande complexidade (crise), o melhor tipo de liderança é a centralizada/autoritária, que, por ser 'rápida' e 'eficaz' (Bass e Stogdill, 1990), se baseia no pressuposto de que um nível de capacidade elevado ultrapassa a compreensão dos trabalhadores, competindo por isso à gestão entendê-lo e levar a cabo o planeamento estratégico que depois será desdobrado em tarefas simples executáveis pelos trabalhadores.

Da justaposição de tese e antítese, podemos retirar que a turbulência sentida na envolvente e a complexidade organizacional tornam as tarefas de gestores e trabalhadores pouco susceptíveis de planeamento prévio por parte de uns ou de outros (Moorman e Miner, 1998). Neste caso, quer a ges- 
tāo quer os trabalhadores 'planeiam em tempo real', mas fazem-no em relação a eixos de acção distintos. Os gestores estão mais preocupados com inovaçōes a nível organizacional e macro-ambiental (grandes tendências envolvente contextual), enquanto que os trabalhadores se preocupam com inovações a nível de mercado/produto e a nível micro-ambiental (pequenas tendências - envolvente transaccional) (Crossan e Sorrenti, 1997). A motivação é aqui potencialmente maior do que em qualquer dos casos anteriores, já que para além da autonomia decorrente da liberdade de planeamento, um novo elemento do modelo de Hackman e Oldham (1980) é activado: o feedbock. A convergência do planeamento e da execução dá a quem a pratica um feedbock imediato das suas aç̧ões e decisões (Gardner e Rogoff, 1990). À crescente velocidade e complexidade da envolvente, a organização responde com planeamento em tempo real, quer ao nível estratégico quer ao nível operacional, maximizando a capacidade de adaptação (para um aprofundamento, ver Cunha, Cunha e Correia, 1999).

\section{TESE (A2): NAS ORGANIZAÇŌES DO FUTURO SERÁ PRIVILEGIADA A EFICÁCIA — OS GESTORES DEVERÃO 'FAZER AS COISAS CERTAS'}

Esta abordagem afirma que a envolvente é uma fonte constante de turbulência e de mudança. Para sobreviver, a organização está sujeita ao 'efeito da rainha de copas' (Kauffman, 1995): para ficar no mesmo sítio (posição competitiva) tem que estar sempre a correr (inovar/mudar). A competência nuclear das organizações neste tipo de envolventes é a de explorar por investigação, ou seja, a de procurar ou criar novas tecnologias, mercados ou produtos (Hamel e Prahalad, 1994). A eficácia é o seu valor guia, já que a eficiência pode, neste tipo de envolventes, resultar rapidamente numa situação em que a empresa se está a esforçar por produzir e vender cada vez melhor um prođuto que já ninguém quer. Recorrendo à definição de Peter Drucker (1993), o papel de quem dirige organizações neste tipo de envolventes é o de 'líder' é aquele que impele à mudança, aquele que se preocupa com 'fazer as coisas certas' (do the right thing). Adoptando um modelo teleológico de mudança (Van de Ven e Poole, 1995), a sua função reparte-se pelas seguintes responsabilidades: (1) conceber um estado futuro; (2) veicular uma percepção do estado actual; e (3) incentivar a mudança. Conceber um estado futuro assenta 
essencialmente em construir uma visão adequada, por um lado, ao estado futuro esperado da envolvente e, por outro, às necessidades e aspirações partilhadas pelos membros da organização (Collins e Porras, 1997). Veicular uma percepção do estado actual implica, essencialmente, transmitir um sentimento de desconforto com o presente e de urgência de mudar (Van de Ven e Poole, 1995), enfatizando a distância entre este e o estado futuro desejado. Incentivar a mudança assenta essencialmente em criar histórias e mitos organizacionais que recompensem comportamentos pró-mudança, permeabilizando a organização para este processo, via cultura (Senge, 1990). É de notar, no entanto, que alguns autores (e.g. Fritz, 1989) defendem que a mera existência de uma percepção de um estado actual diferente de um estado futuro desejado é suficiente para despoletar a mudança, carecendo este processo de qualquer incentivo. Em suma, esta corrente defende que a função central de quem dirige a organização se reporta à gestão dos seus negócios futuros - ou seja, à maximização da capacidade de gerar lucros (profitability). A organização sobrevive, gerando 'estrelas', mas sempre à custa de sacrifícios de rentabilidade que, em última análise, a podem esvaziar de recursos, pondo em causa a sua longevidade.

\section{ANTÍTESE (A2): NAS ORGANIZAÇŌES DE SUCESSO É PRIVILEGIADA A EFICIẼNCIA — OS GESTORES DEVEM 'FAZER AS COISAS BEM'}

Esta abordagem afirma que a envolvente se caracteriza por períodos de estabilidade interrompidos por surtos esporádicos de turbulência e de mudança. A competência nuclear das organizações neste tipo de envolventes é a de explorar por utilização, ou seja a de rentabilizar as suas tecnologias, mercados ou produtos correntes, até à próxima descontinuidade, altura em que devem procurar adaptar-se o melhor possível (Romanelli e Tushman,

128 1994). A eficiência é o seu valor guia, já que procurar a eficácia em envolventes de grande concorrência pode resultar rapidamente numa situação em que a empresa se está a esforçar por produzir e vender produtos cada vez melhores que ninguém tem dinheiro para comprar. Voltando à definição de Peter Drucker (1993), o papel de quem dirige organizaçōes neste tipo de envolventes é o de 'gestor' - é aquele que impele à maximização dos resultados em simultâneo com a minimização dos inputs, aquele que se preocupa com 'fazer 
as coisas bem' (do things right). Esta função reparte-se nas seguintes tarefas: ( 1 ) planeamento: (2) implementação; e (3) controlo (Fayol, 1949). No planeamento, o gestor traça os objectivos da organização e os processos mediante os quais esses objectivos vão ser alcançados. $\mathrm{Na}$ implementação, põe esses sistemas em funcionamento. No controlo verifica se o processo corre como planeado e introduz as correç̧ões necessárias para garantir que os objectivos iniciais são atingidos. Sinteticamente, esta abordagem afirma que a função central de quem dirige a organização se reporta à gestão dos seus negócios actuais - ou seja, maximizar o lucros (profit). A organização prospera gerando 'vacas leiteiras', mas sempre à custa da sacrificios de flexibilidade que, em última análise, a podem esvaziar de mercado (e, consequentemente, de recursos), pondo em causa a sua longevidade.

\section{SINTTESE (A2): NAS ORGANIZAÇŌES É PRIVILEGIADA A EFICÁCIA EFICIENTE — OS GESTORES DEVEM 'FAZER BEM AS COISAS CERTAS'}

Aqui defendemos que a envolvente se caracteriza por periodos de mudança incremental contínua que vai gerando surtos infrequentes de turbulência e de mudanças radicais. A competência nuclear das organizaçōes neste tipo de envolventes é a de explorar por utilização a exploração por investigação, ou seja a de rentabilizar as novas tecnologias, mercados ou produtos que descobriu ou criou (Brown e Eisenhardt, 1997). A eficácia eficiente é o seu valor guia. Ainda com base em Drucker (1993), o papel de quem dirige organizações neste tipo de envolventes é o de 'líder gestor' - é aquele que impele à descoberta de novas oportunidade que possam ser transformadas em motores (geradores) de lucro, aquele que se preocupa em 'fazer bem as coisas certas' (do the right thing right). Esta função reparte-se nas seguintes tarefas: (1) catalisar a construção de uma visão orientadora: e criar uma cultura de (2) mudança e de (3) obtenção de resultados. Catalisar a construção de uma visão orientadora significa participar na actividade de construção de significado (sensemaking) da organização, de forma a que a interpretação imposta sobre o padrão de acções desta tenha uma valoração positiva partithada pelos seus membros, capaz de servir como mecanismo de coordenação da sua acção futura e de input para futuras construções de significado, reforçando o seu papel (Weick, 1979). Criar uma cultura de mudança é impor- 
tante para fomentar a actividade de exploração por investigação e reporta-se, como já foi dito, a criar histórias e mitos organizacionais que valorem positivamente comportamentos pró-mudança, permeabilizando a organização para este processo, através da cultura (Senge, 1990). Criar uma cultura de obtenção de resultados tem como objectivo fomentar a actividade de exploração por utilização, de modo a que as oportunidades descortinadas no processo centrado na eficácia, possam ser rentabilizadas alimentando de novo esse processo. Em resumo, esta abordagem afirma que a função central de quem dirige a organização diz respeito à gestão dos seus negócios actuais de forma a gerarem negócios futuros - ou seja, maximizar a lucratividade dos lucros (profitoble profitability). A organização sobrevive e prospera gerando vacas leiteiras estrelas', explorando por utilização as oportunidades que vai descortinando via exploração por investigação o que, em última análise, Ihe vai repondo recursos e promovendo a longevidade (sobre esta tensão, considere-se também o caso das 'organizações imaginárias', estudadas por Bo Hedberg [e.g. Hedberg e Holmqvist, 1999]).

\section{TESE (A3): NAS ORGANIZAÇŌES DO FUTURO A MUDANÇA SERÁ INCREMENTAL}

A cada uma das correntes consideradas, está subjacente um pressuposto em relação à natureza da inovação/mudança. As abordagens que aqui designamos por modernas afirmam que o sucesso e até a própria sobrevivência da organização só são possíveis se esta inovar continuamente (Peters, 1992; Imai, 1989). Isto deve-se, essencialmente, à redução dos ciclos de vida: (1) dos produtos, gerada quer (a) pela concorrência acrescida que se tem vindo a sentir em muitos sectores, quer (b) por alterações qualitativas cada vez mais frequentes nos padrōes de procura (D'Aveni, 1994); (2) das tecnologias de produção, que resulta essencialmente da concorrência que se faz sentir nesses

130 sectores (Bettis e Hitt, 1995); e (3) das práticas de gestão/administrativas. essencialmente induzida pela indústria da consultoria (Abrahamson, 1991). Isto implica que essa inovação não deve ficar só pela oferta ao cliente, mas também abarcar todo o processo de produção e entrega dessa oferta, incluindo a organização que the está subjacente. Estas inovações podem ser de índole incremental ou radical, mas devem sempre resultar num fluxo contínuo de mudança. Normalmente estes dois tipos aparecem como exclusivos, ou 
seja para alguns autores só faz sentido a mudança radical (Hamel e Prăhalad, 1994), enquanto que para outros só o faz a incremental (Imai, 1989). Do nosso ponto de vista, e apesar do optimismo de alguns autores (DeBono, 1986), a pressão para a 'produção' de inovações/mudanças a uma cadência acelerada ultrapassa a capacidade humana, quer ao nível do indivíduo quer do grupo, de 'desaprender' de maneira fundamental, os modelos mentais desenvolvidos em relação à indústria onde trabalham (Argyris, 1985) - a mudança coritínua tende a ser, por isso, incremental.

ANTITESE (A3): NAS ORGANIZAÇŌES DE SUCESSO A MUDANCAA É PONTUADA

Partindo da mesma percepção do panorama competitivo mencionada acima, a corrente de pensamento que aqui designamos como tradicional tem uma perspectiva oposta à anterior (e.g. Porter, 1998). Esta abordagem afirma que a única mudança relevante na envolvente é a mudança radical, já que é esta que detém o poder de deixar a organização órã de mercado (Hamel e Prahalad, 1994). Além disso, defende que este tipo de mudança ocorre infrequentemente e é mediado por períodos mais ou menos longos de estabilidade. Tendo isto em conta, a organização, além de tomar partido destes períodos de estabilidade, deve, perante mudanças radicais na envolvente, operar também em si uma mudança deste tipo, para sobreviver, retornando depois a um período de estabilidade (Van de Ven e Poole, 1995).

As inovaçōes/mudanças nas empresas ocorrem, assim, de forma pontuada e são de natureza radical.

SINTTESE (A3): NAS ORGANIZAÇŌES A MUDANÇA É INCREMENTALMENTE PONTUADA.

Mantendo a percepção de hipercompetitividade na envolvente (D'Aveni, 1994), podemos dividir as mudanças que esta provoca em dois tipos, uma (I) incremental/contínua, de índole essencialmente quantitativa cuja sedimentação, ao longo do tempo, faz emergir mudança (2) pontuada/radical, de índole qualitativa.

O desafio que se coloca às organizações é, por conseguinte, o de importar este processo, levando a cabo mudanças incrementais de forma contínua, 
fazendo emergir no seu interior, agora de forma pontuada, mudanças radicais (Brown e Eisenhardt, 1997; Eisenhardt e Tabrizi, 1995).

TESE (A4): NAS ORGANIZAÇÕES DO FUTURO A PRIMAZIA SERÁ DADA Á EXCELÊNCIA NAS COMPETENCIAS E NOS CONHECIMENTOS

Baseando-se de novo na turbulência sentida na maioria das envolventes actuais (D'Aveni, 1994) e na necessidade de eficácia organizacional que esta acarreta, esta abordagem defende a primazia do conhecimento/competências em relação à tecnologia/inputs. $\mathrm{A}$ argumentação subjacente $\mathrm{a}$ esta proposição diz que a eficácia resulta de uma ideia clara e economicamente factível de um estado futuro desejado e do desenvolvimento de um processo que o permita atingir. A concepção do estado futuro requer uma percepção clara/partilhada da envolvente, e das tendências que nela vão emergindo, assentando por isso na capacidade de evitar enviesamentos de percepção oriundos de rotinas defensivas (Argyris, 1985) e a capacidade de aprender em grupo (Senge, 1990, Bohm, 1996). A concepção do processo para atingir a visão desejada é. na sua essência, um exercício de criatividade. A proficiência da organização no desempenho desta competência depende basicamente da diversidade que detém no seu interior, e da sua capacidade de a potenciar por interaç̧ão dos seus membros (Amabile, 1998; Baker, 1994). Daqui resulta que, para que a organização seja eficaz, é mais importante a diversidade do seu stock de conhecimento e as competências de criatividade e aprendizagem dos seus membros, do que a abundância de inputs ou a presença de uma tecnologia muito sofisticada. Em última análise, as competências e o conhecimento são privilegiados porque são mais flexíveis e estão mais orientados para a exploração por investigação, enquanto que inputs e tecnologia possuem um maior grau de inércia e estão mais orientados para a exploração por utilização.

ANTITESE (A4): NAS ORGANIZAÇÕES DE SUCESSO A PRIMAZIA É DADA Á EXCELÊNCIA NA TECNOLOGIA E NOS INPUTS

Esta corrente, ao contrário da anterior, retira da turbulência sentida na maioria das envolventes actuais, a necessidade de uma maior eficiência - 0 
aumento da concorrência implica ou a produção de produtos mais baratos ou a de produtos de melhor qualidade (física) (Porter, 1998). Este aumento de eficiência pode resultar essencialmente de dois factores: ( 1 ) de uma maior eficiência na obtenção de inputs (mais baratos ou de melhor qualidade) conseguida através de alianças com fornecedores, metodologia just-in-time, etc. (Peters, 1987); ou de uma maior eficiência no processo (custos mais baixos. melhor qualidade física), que assenta fundamentalmente na tecnologia utilizada (em sentido amplo, ou seja, hardware - máquinas - e software - organização do trabalho [Juran, 1988; Deming, 1986; Imai, 1989]). Donde resulta que, para que a organização seja eficiente, são mais importantes os inputs e a tecnologia utilizada, visto que são mais especializados e orientados para a exploração por utilização do que a diversidade do seu stock de conhecimento e as competências de criatividade e aprendizagem dos seus membros, que são mais horizontais e estão mais orientadas para a exploração por investigação.

SINTESE (A4): NAS ORGANIZAÇŌES A PRIMAZIA Ė DADA À EXCELENCIA NO BRICOLAGE (EXCELENCIA NO CONHECIMENTO PARA TER EXCELENCIA NA TECNOLOGIA)

Da necessidade de reagir em tempo real a alterações na envolvente, e de procurar a 'eficácia eficiente', advém a necessidade de resolver problemas e aproveitar oportunidades sem que estejam disponíveis os recursos óptimos para o efeito (Weick. 1993). Para que isto seja possível, é necessário que a empresa (1) possua um conjunto mínimo de recursos horizontais críticos (Weick, 1993): (2) a competência e o conhecimento suficiente desses factores para os afectar às tarefas necessárias à exploração por utilização de oportunidades/problemas detectados na envolvente (Eisenberg, 1990); (3) uma percepção compatível do estado futuro desejado (Bastien e Hostager, 1988). Em suma, deste ponto de vista, a competência e o conhecimento são capazes de 'horizontalizar'/generalizar um conjunto limitado de recursos, de modo a que sejam suficientemente flexíveis para serem adaptáveis a qualquer oportunidade/problema (permitir a exploração por utilização), servindo esses recursos como uma fonte de coordenação entre os membros de uma organização, de forma semelhante ao papel desempenhado pela pauta de uma canção para um grupo de improvisadores de jazz, por oposição ao papel que esta desempenha para uma orquestra (Weick, 1999). 
TESE (A5): NAS ORGANIZAÇŌES DO FUTURO OUVIR-SE-Á O MAXIMO DE PESSOAS POSSIVEIS, AO MÁXIMO

Esta proposição assenta em dois argumentos. Por um lado, o aumento da complexidade externa (contextual e transaccional), em especial no que se reporta às alterações dos padrões de consumo, implica que a empresa desenvolva esforços deliberados para ter uma comunicação estreita com o seu mercado, de forma a que as suas inovações sejam bem sucedidas (Kotler. 1992). Por outro lado, o aumento da complexidade interna leva a que ( 1 ) apareçam problemas não antecipáveis no interior das organizações (Stacey, 1996) e que (2) esses problemas não sejam resolúveis pela vontade ou acção de um indivíduo isoladamente. Isto implica que a gestão da organização deve manter canais de comunicação directos com várias partes da organização de modo (I) a detectar potenciais problemas/oportunidades (Peters e Waterman, 1982) e (2) facilitar a implementação e adopção de soluções/inovações para enfrentar esses problemas/oportunidades. Em síntese, o topo da organização deve procurar ouvir continuamente os seus restantes membros, e a empresa como um todo deve ter a mesma preocupação em relação ao mercado que serve (e.g. Kohli e Jaworski, 1990).

\section{ANTITESE (A5): NAS ORGANIZAÇŌES DE SUCESSO NĀO SE OUVE NINGUÉM}

A corrente tradicional adopta uma posição simétrica à anterior. Em relação à complexidade externa, e tendo em conta que, para esta corrente, a inovação/ mudança ocorre de forma pontuada e é de natureza radical, esta defende que compete às organizações antecipar a procura e criar necessidades (Hamel e Prahalad, 1994). 'Ouvir' os destinatários da inovação é uma etapa que ocorre já muito no fim do seu processo de desenvolvimento (Cooper, 1994). No que diz

134 respeito à complexidade interna, esta corrente partilha de uma visão contingencial da organização (Lawrence e Lorsch, 1967). Todas as formas organizacionais têm vantagens e inconvenientes - compete à gestão, depois de analisada a envolvente, decidir qual a melhor forma e a partir daí viver com tudo o que esta tem de positivo e de negativo. Em suma, a organização pode (e deve) ter um comportamento quase autista, quer no que diz respeito ao que se passa no seu interior, quer no que diz respeito ao mercado que serve. 
Do confronto das duas posições anteriores, emerge uma abordagem que permite entender o sucesso de algumas inovações, que as restantes deixam sem explicação (como é o caso da introdução do 'rato' na interface entre computador e utilizador [Levy, 1995]). Ao nível da complexidade externa, ouvir algumas pessoas, algumas vezes, implica escutar activamente clientes (actuais/futuros) relevantes, procurando as suas necessidades subjacentes, muitas vezes não articuláveis, mas depois a organização deve assumir uma posição autista, de forma a estar livre para encontrar soluções criativas que atendam a essas necessidades, testadas através da experimentação (Peters, 1992; Weick, 1999). Em relação à complexidade interna, esta postura implica procurar também o que está subjacente aos problemas/oportunidades levantados pelos trabalhadores, e servir de catalisador no processo de criação de significado, de forma a enquadrar esses desafios, permitindo que sejam os próprios membros a planear a melhor maneira de os enfrentar, à medida que a acção se desenrola. Trata-se então de praticar um 'autismo aberto', quer nas relações intra-organizacionais, quer nas relações empresa-mercado.

\section{ORGANIZAÇÃO}

TESE (BI): NAS ORGANIZAÇŌES DO FUTURO O TRABALHO SERÁ EM EQUIPA

Uma das decisões que a maioria dos manuais apresenta como fazendo parte da gestão de topo, reporta-se à afectação de determinadas tarefas à equipa ou ao indivíduo.

As correntes mais recentes de gestão, em especial as de índole normativa, têm apregoado as vantagens do trabalho em equipa, argumentando que a complexidade da envolvente deve ser complementada com complexidade organizacional. Consequentemente, as tarefas que incluem pontos de interacção com a envolvente devem ser desempenhadas por equipas multifuncionais que, por hipoteticamente possuírem um maior grau de diversidade, são capazes de ter uma percepção mais clara dos sinais enviados pela envolvente e de gerar soluções mais adequadas aos desafios colocados por esta (Katzenbach e Smith, 1994). Peters chega mesmo a afirmar (e literalmente a sublinhar) que 
'a força do conceito de equipa é tal que na maior parte das vezes é aconseIhável violar o aparente senso comum e forçar uma estrutura de equipa em quase todas as actividades' (1987: 302). Para esta corrente teórica, é a equipa, e não o indivíduo, que constitui o elemento nuclear de uma organização.

ANTITESE (BI): NAS ORGANIZAÇÕES DE SUCESSO O TRABALHO É INDIMDUAL

A teoria tradicional centra-se no indivíduo (e.g. Taylor 191 I: Fayol, 1949), preocupando-se apenas com grupos e equipas na medida que estes afectam a racionalidade e desempenho deste. Assim, para esta corrente, os grupos possuem desvantagens que os tornam perigosos para enfrentar um ambiente em mudança. A sua criatividade é menor do que a do indivíduo, e estão impregnados de fenómenos que reduzem a sua racionalidade e conhecimento, na melhor das hipóteses ao nível do pior dos seus elementos. O pensamento grupal (groupthink), que leva à tomada de decisões que do ponto de vista de um observador externo são desprovidas de racionalidade (Janis, 1971), e o Paradoxo de Abilene, segundo o qual um grupo é capaz de empreender um curso de acção não desejado por nenhum dos seus membros individualmente (Harvey, 1996), constituem exemplos deste argumento.

\section{SINTESE (BI): NAS ORGANIZAÇŌES O TRABALHO É INDINIDUAL EM EQUIPA}

Das duas abordagens anteriores, resulta o conceito do individualismo em equipa. A equipa aparece de facto como o elemento nuclear da organização essencialmente porque aglutina a diversidade necessária para uma maior eficácia a nível da tomada de decisão e criatividade (Brown e Eisenhardt, 1997);

136 no entanto, as relações entre os membros da equipa são diferentes da intimidade preconizada pela tese anterior. Aqui, essa relação membro-grupo é de intersecção e não de inclusão (Barrett, 1998), ou seja, o indivíduo contribui para o grupo mas não se the entrega, mantendo assim a distância necessária para que se evite o conjunto de fenómenos de redução de racionalidade e criatividade de que os grupos normalmente padecem. A motivação, satisfação, produtividade, criatividade e racionalidade são, de acordo com esta aborda- 
gem, fenómenos individuais, restringidos ou amplificados pelo grupo (Bastien e Hostager, 1988).

TESE (B2): NAS ORGANIZAÇOES DO FUTURO A CRIATIVIDADE SERÁ PRIVILEGIADA

O tipo de concorrência na maioria dos sectores de actividade gera e é gerada por mudanças descontínuas e que se sucedem a uma cadência elevada (Bettis e Hitt, 1995). Isto tem como consequências, entre outras, (1) uma rápida desactualização dos modelos mentais detidos pelos membros das organizações que os constituem e (2) o aparecimento de oportunidades e problemas - desafios - que não encontram ressonância no passado dessas empresas (Senge, 1990; Peters, 1992).

Para responder a estes desafios, a corrente 'moderna' defende, por um lado, (1) a necessidade de dar uma maior ênfase à aprendizagem de ciclo duplo (eficicácia) em detrimento da aprendizagem de ciclo único (eficiência; Senge, 1990): e, por outro, (2) a necessidade de gerar variedade de pensamentos e comportamentos, de forma a compensar maior complexidade externa com maior complexidade interna. Isto implica que, de acordo com esta abordagem, aos gestores compete criar as condições para a maximização da criatividade na organização (Amabile, 1998), procurando libertar os seus membros de todas as barreiras que inibam o desenvolvimento e aplicação desta competência (Weick, 1999).

A resposta desta corrente de pensamento às elevadas taxas de insucesso diagnosticadas na produção de inovações por parte da organização [Cooper, 1994; Craig e Hart, 1992]) é que os erros são um 'mal necessário' causado por variaçōes (actos criativos) mal sucedidas e compensadas pelos resultados daquelas que são melhor aceites pelo mercado.

ANTITESE (B2): NAS ORGANIZAÇÕES DE SUCESSO A ROTINIZAÇÃO É PRVILEGIADA

Esta abordagem, apesar de não ignorar o acréscimo da concorrência. defende que o seu impacto ocorre essencialmente ao nível do preço e do posicionamento (Porter, 1998), o que significa que o desafio que se coloca à empresa não é o da diferenciação pela criação de algo de novo, mas sim por 
fazer melhor o que já faz, ou seja, ou fazer melhor o seu produto/serviço, reduzindo o seu custo, ou fazer um produto/serviço melhor (qualidade na percepção do cliente) mantendo um posicionamento sustentável e rentável. Contudo, e como resposta aos sucessivos ataques de que esta perspectiva tem sido vítima, Porter (1996) parece contrariar esta perspectiva ao distinguir estratégia de eficácia operacional. No entanto, mantém uma relação implícita entre ambas, em que a segunda é condição sine qua non da primeira e continua a defender a estratégia como criação de uma posição de valor única, por via de um conjunto de actividades distintas das da concorrência. Apesar desta reformulação, essa posição única acaba por se reportar às duas categorias anteriores de diferenciação com base no custo ou na qualidade do produto que sustentam a escolha de mercados/nichos a servir pela empresa. Em ambos os casos estamos assim perante um aumento de eficiência, obtida através da rotinização - normalmente ao nível do processo -, que pode ser quantitativa (redução do custo), ou qualitativa (aumento da qualidade do produto/serviço) (Deming, 1986).

A criatividade tem algum espaço neste tipo de abordagens - quando, por exemplo, a empresa altera radicalmente o seu posicionamento competitivo - mas é sempre muito infrequente e por isso mais característica da obtenção de um equilíbrio pontuado do que de uma mudança incremental (Eisenhardt e Tabrizi, 1995).

Os erros não têm aqui lugar devido ao elevado grau de prescrição que caracteriza todo o processo de produção, implementado directa (via supervisão) ou indirectamente (via estandardização [Juran, 1988]).

SÍNTESE (B2): NAS OR.GANIZAÇÔES A ROTINIZAÇĀO DA CRIATIMIDADE É PRIVILEGIADA

Das correntes anteriores, podemos retirar as pressōes que a turbulência da envolvente impõe às organizações no sentido de uma mudança próxima do contínuo. Há também que ter em conta que este padrão de comportamento necessita de uma determinada dotação de recursos se as novas oportunidades que vai descortinando forem exploradas por utilização, ou seja se forem rotinizadas de forma a serem suficientemente rentáveis. Isto significa que à aprendizagem de ciclo duplo (eficácia) - à descoberta de novas oportunidades - deve sempre seguir-se a de ciclo único (eficiência) - o apro- 
veitamento/rentabilização dessas oportunidades (Moorman e Miner, 1998). Trata-se então de maximizar a criatividade rotinizada, ou seja maximizar o número de oportunidades aproveitadas e não apenas o número de oportunidades geradas/descobertas (Barrett, 1998). Neste âmbito, os erros são vistos como oportunidades que devem ser aproveitadas (também, mas não só, para aprender; Weick, 1999). Trata-se então de promover a mudança incremental de forma a gerar mudanças radicais. Usando uma metáfora empregue por Peters (1992), o gestor aqui assemelha-se a um jardineiro que deve não só olhar para o que semeou, como também para as plantas que vão aparecendo alheias à sua intenção, já que estas podem transformar a beleza do seu jardim da elegância de uma capa de revista para a complexidade da vida real.

TESE (B3): NAS ORGANIZACCÕES DO FUTURO O TREINO SERVIRÁ PARA UBERTAR OS TRABALHADORES

A teoria dita 'moderna' partilha do conjunto de crenças e valores que McGregor (1960) rotulou de Teoria Y. Consequentemente, acredita também que as organizações devem limitar a liberdade dos seus membros apenas pelo período de tempo necessário para que estes adquiram as competências requeridas para canalizar adequadamente o seu desempenho. A partir do momento em que estas competências estão presentes, essa limitação deve ser levantada, de forma a que os membros da organizaçāo possam aplicar todo o seu talento (Deming, 1986). O treino é entendido essencialmente como um processo de aquisição de competências e de crenças e valores (cultura) que os libertem para desempenhar as suas tarefas de forma excelente (Peters e Waterman, 1982). Os empregados não cometem erros, porque sabem como não o fazer.

ANTITESE (B3): NAS ORGANIZAÇŌES DE SUCESSO O TREINO SERVE PARA RESTRINGIR OS TRABALHADORES

Este tipo de abordagens partilha, por oposição às anteriores, das crenças e valores em relação à natureza humana que McGregor (1960) rotulou de Teoria X. Por esta razão, o treino/formação tem como principal função a de assegurar a afectação de esforço/trabalho por parte dos trabalhadores à pros- 
secução dos objectivos organizacionais definidos pelo topo. Quando o treino é concluído, é necessária a aplicação continuada de mecanismos de controlo para assegurar a manutenção da cooperação dos trabalhadores (Mintzberg, 1995). O treino é entendido como um processo de reforço da coordenação, que visa tornar previsível o comportamento dos indivíduos através da estandardização de ( 1 ) competências e de (2) crenças e valores. Os empregados não cometem erros porque não têm autonomia para o fazer.

SINTESE (B3): NAS ORGANIZAÇŌES DE SUCESSO O TREINO SERVE PARA LIBERTAR OS TRABALHADORES, RESTRINGINDO-OS

De acordo com esta corrente, a liberdade dos trabalhadores só necessita de ser limitada de forma visível enquanto não forem criados mecanismos de coordenação invisiveis, ou seja enquanto os membros não possuam visões compatíveis da realidade nem um objectivo comum. $\mathrm{O}$ objectivo do treino, que se faz mais durante o desempenho enquanto membro de uma comunidade de prática (Bastien e Hostager, 1988) do que em sala, é o de dotar os indivíduos com um objectivo socialmente partilhado e com um conjunto mínimo de regras de interacção social que assegure a coordenação entre os esforços individuais via compatibilização da acção, sem no entanto criar uma percepção de limitação da liberdade individual (Weick, 1993, Cunha, Cunha \& Kamoche, 1999), garantindo assim que os indivíduos afectam o seu nivel mais elevado de desempenho à prossecução desse objectivo (Eisenberg, 1990). Os indivíduos não cometem erros, já que qualquer variação inesperada é utilizada como fonte de aprendizagem e de mudança, ou seja porque os erros não existem.

TESE (B4): NAS ORGANIZAÇÕES DO FUTURO A COORDENAÇÃO SERÁ FEITA VIA ACÇÃO

A turbulência ambiental a que são sujeitas e a idade de um número elevado de organizações (Baker, 1994; Greiner, 1972), em conjunto com a presença cada vez mais intensa de mecanismos de pressão para a difusão de inovaçōes administrativas/organizacionais (Abrahamson, 1991), tem levado ao aumento das pressões para a adopção de novas formas organizacionais. Recentemente, essa pressão levou a que os esforços de inovação organizacio- 
nal/administrativa atingissem um nivel mais fundamental, ao abandonar os esquemas de coordenação com base no binómio hierarquia/poder, que tem vindo a dominar o design organizacional (Powell, 1990). adoptando-se novas abordagens que se baseiam nos dois outros mecanismos de coordenação conhecidos: o mercado e a rede.

No que se refere ao mercado, a coordenação é explicada pela necessidade que os seus membros têm dos recursos (financeiros) uns dos outros para levarem a cabo os seus objectivos individuais (Hayek, 1988), conduzindo à emergência (ou ao desenvolvimento deliberado, se a gestão de topo da organização for entendida como um centro de proveito, que 'vende' capital) dos objectivos da organização através de uma 'mão invisivel', em tudo semeIhante ao mecanismo do mesmo nome descrito por Adam Smith. Numa organização, os diversos membros estão coordenados entre si devido à necessidade de obter cooperação dos outros para alcançar os seus objectivos individuais (o imperativo tecnológico defendido por Barnard [1938]). Os indivíduos vão assim construindo um stock de direitos de reciprocidade e de reputação, e precisam de cooperar com os restantes membros da rede (contribuir para o cumprimento dos objectivos destes) para aumentar esse stock (Baker, 1994). Os objectivos organizacionais emergem (ou são deliberadamente desenvolvidos, se impostos por pessoas ou entidades externas à organização) através de uma 'mão invisível' cujo mecanismo de coordenação não é mais o preço, mas a confiança/reputação (Powell, 1990). Em ambos os casos, a consecução dos objectivos organizacionais que vão emergindo, processa-se sem a necessidade da presença deliberada de mecanismos de controlo, visíveis ou invisíveis. De facto, a presença de qualquer destes mecanismos numa organização é desnecessária e perigosa.

É desnecessária já que, como foi explicado acima, o preço (no mercado) e a confiança/reciprocidade (na rede) asseguram a coordenação suficiente entre os seus membros. É perigosa porque esta abordagem, que aqui designamos por moderna, afirma que nas organizaçōes deve existir/ser gerada a variedade necessária para que os processos de selecção operados pela envolvente disponham de 'material genético' suficiente para encontrar inovações legitimáveis pelo mercado.

Para que esta diversidade seja possível, os mecanismos de coordenação organizacional devem ser não-intrusivos, ou seja, a sua presença não se pode fazer sentir de forma alguma entre os membros da organização e devem pro- 
mover a diversidade (Semler, 1995; Powell, 1990). A perspectiva dos 'mercados internos' afirma que a promoção da diversidade só aparece se a coordenação entre as unidades intraorganizacionais for feita com base no preço, e se a essas unidades for dada a liberdade de escolher entre fornecedores e clientes no seu 'mercado interno' e no mercado externo (Halal, Geranmayeh e Pourdehnad 1993). A perspectiva das organizações em rede afirma que indivíduos que exerçam tarefas com uma elevada componente de conhecimento. não estão dispostos a ver a sua actividade ser fonte de qualquer tipo de controlo, por mais invisível que seja (Drucker, 1994). A coordenação entre estes indivíduos é feita com base na reprocidade, confiança e expectativas mútuas (Fukuyama, 1995). Deste modo, qualquer tentativa de imposição de um sistema de controlo, por mais invisivel que seja (Perrow, 1986), nestas formas organizacionais, limitaria a sua capacidade de gerar variedade, de responder reactiva ou proactivamente à envolvente e, em última análise, de sobreviver Finalmente, para esta corrente, alcançar o propósito da organização passa essencialmente pelas relações informais entre os seus membros (Pfeffer: 1992), em detrimento das relações formais entre estes, que devem ser eliminadas sempre que possível (Forrester, 1965).

ANTITESE (B4): NAS ORGANIZAÇÕES DE SUCESSO A COORDENAÇÃO É FEITA VIA ESTRUTURA

A crescente turbulência sentida na maioria das envolventes implica que só alguém com uma visão de conjunto (de topo) é capaz de conceber objectivos adequados para o sucesso da organização. É também da competência desta entidade a implementação dos mecanismos que asseguram que o esforço de toda a organização se encontra dirigido para esses objectivos. A coordenação entre os membros de uma organização deve assentar, por 142 isso, num de dois processos: ( 1 ) a ordem, que entendemos aqui como substituição de conhecimento (Follett, 1940b) ou (2) a partilha do conhecimento (Mintzberg, 1995). Dizemos que a coordenação é feita via ordem/substituição do conhecimento quando é implementada durante o processo de prossecução dos objectivos organizacionais. Nesta categoria incluem-se a supervisão directa (substituição total do conhecimento) e a estandardização de outputs ou processos (substituição parcial do conhecimento). Dizemos que a coorde- 
nação é feita via partilha de conhecimento quando é assegurada no momento da entrada do indivíduo para a organização - estandardização de competências - ou imediatamente a seguir - estandardização de cultura/ideologia. Independentemente do mix de mecanismos de controlo escolhido, o que importa é limitar a variedade de comportamentos e objectivos individuais, de forma a que os resultados que a gestão de topo prescreve para a empresa sejam alcançados com o máximo de precisão e eficiência. Para esta abordagem, $\mathrm{o}$ alcance destes objectivos passa essencialmente pelas relações formais entre os seus membros, em detrimento das relações informais entre estes, que são vistas como um mal necessário inerente à condição humana, que desejavelmente seria eliminado (Fayol, 1949).

SÍNTESE (B4): NAS ORGANIZAÇŌES A COORDENAÇĀO É FEITA VIA ACÇÃO ENQUADRADA NUMA ESTRUTURA FORMAL MINIMA

A turbulência da envolvente leva a que a acção realizada da organização seja não só resultado das suas intenções, como também de uma forte componente emergente. Os objectivos organizacionais emergem assim à medida que os indivíduos atribuem significado (sensemaking) à sua acção conjunta e às suas intenções prévias (Weick, 1999). A coordenação entre os membros da organizaçāo assenta deste modo em três elementos: (1) uma estrutura mínima de regras/padrões de relacionamento formalizados; (2) de objectivos pessoais compatíveis; e (3) de uma percepção compatível em relação aos desafios da envolvente (Weick, 1993). Esta coordenação é sempre invisível, e tem como objectivo fornecer à organização a estandardização mínima que, ao não inibir a diversidade e a geração de variedade (por ser mínima), permite que estas sejam convenientemente aproveitadas, através da aprendizagem/criação de rotinas (por ser estandardização). $O$ modelo de base é o da comunidade de prática (Barrett, 1998), onde existe, por um lado, um conjunto de regras partilhadas que dizem essencialmente respeito à interacção social e, por outro, um núcleo de saber repartido por todos os membros - dados como adquiridos quando existe interacção entre eles.

Deste modo, os objectivos organizacionais são realizados na medida em que resultam da intersecção (parcela compatível) dos objectivos individuais e porque são maioritariamente articulados retrospectivamente. Para esta abor- 
dagem, o alcance destes objectivos passa essencialmente pela criação de estruturas mínimas (Kamoche e Cunha, 2000) que potenciem e facilitem as relações informais entre os seus membros.

\section{TESE (B5): NAS ORGANIZAÇŌES DO FUTURO A LIDERANÇA SERÁ DEMOCRÁIICA}

Como foi explicado anteriormente, esta corrente defende que devem ser os trabalhadores a planear e executar as tarefas necessárias à eficácia da empresa. Isto implica que a liderança deste tipo de organizações, conforme tem vindo a ser visível ao longo do texto, deve possuir um conjunto de características essenciais ao seu sucesso. A base/motivação de quem lidera pessoas neste tipo de organizações é a aspiração de servir (Greenleaf, 1977). O que significa que o líder percepciona o seu papel como o de permitir que os outros (seus 'seguidores') tenham um desempenho excepcional. A sua tarefa principal é, assim, assegurar-se que todos os indivíduos têm as condições necessárias para a realização plena do seu potencial. Motivar (através do exemplo) e ajudar os outros a praticar desenvolvimento pessoal (personal mastery) são, por isso, as tarefas mais importantes do líder (Senge, 1990). Deste processo, o líder vê essencialmente satisfeitas as suas necessidades de pertença (Maslow, 1970), através das relações de suporte que estabelece com os seus seguidores. Este tipo de líder é por isso essencialmente motivado pela necessidade de afiliação (de acordo com a tipologia de McClelland [1961]).

\section{ANTITESE (B5): NAS ORGANIZAÇŌES DE SUCESSO A LDERANÇA É AUTORITÁRIA}

Esta abordagem afirma que compete ao líder planear as tarefas que os trabalhadores vão executar, de modo a garantir a eficiência da empresa. Isto implica que a liderança deste tipo de organizações, conforme também pode ser detectado ao longo do texto, tem um leque diferente de características essenciais ao sucesso. A base/motivação do líder, neste tipo de organizações, é a aspiração de ser servido/de exercer poder. Isto significa que o líder percepciona o seu papel como o de procurar obter e demonstrar um desempenho pessoal excepcional. A sua missão principal é, assim, assegurar-se que todos os individuos cumprem as tarefas que prescreveu, de forma a con- 
cretizar os objectivos da organização. A implementação e controlo são, deste modo, as suas funções mais importantes (juntamente com o planeamento, se este estiver incluído nas suas responsabilidades). Deste processo, o líder vê essencialmente satisfeitas as suas necessidades de reconhecimento (Maslow. 1970), através das relações de poder que estabelece com os seus subordinados. Este tipo de líder é por isso essencialmente motivado pela necessidade de poder (de acordo com a tipologia de McClelland [1961]).

SINTESE (B5): NAS ORGANIZAÇŌES A LIDERANÇA É DEMOCRATICAMENTE AUTORITÁRIA

Esta corrente defende que quer os trabalhadores, quer os gestores têm como tarefa o planeamento em tempo real, ou seja, a convergência dos planos com a sua execução. Desta forma, o líder, neste tipo de organizaçōes, deve possuir um conjunto de características essenciais ao sucesso, diferentes das patentes nas duas correntes anteriores. A base/motivação da liderança neste tipo de organizações é a aspiração de servir o grupo (que neste caso inclui o líder [Eisenberg, 1990]). Isto significa que o líder percepciona o seu papel como o de permitir que o grupo a que pertence, no seu conjunto, tenha um desempenho excepcional. A sua tarefa principal é, assim, dupla. Por um lado, (1) quando é o principal actor do grupo, deve assegurar-se que as suas intenções são entendidas por este, de forma a que os restantes membros possam contribuir para a excelência do seu desempenho, e que este contribua para a do grupo. Por outro lado, (2) quando é outra pessoa que assume esse papel, o 'ex-líder' passa a contribuir para o desempenho desta, contribuindo indirectamente para o do grupo. Deste processo, o líder/seguidor vê essencialmente satisfeitas as suas necessidades de realização (Maslow, 1970), através das relaçōes de suporte que estabelece com os seus seguidores. Este tipo de líder é por isso essencialmente motivado pela necessidade de realização (de acordo com a tipologia de McClelland [ $196 \mid])$.

\section{CONCLUSÃo}

As perguntas 'como?' (organização) e 'o quê?/porquê?' (estratégia) têm vindo a ser, senão dos mais prementes, pelo menos dos mais estudados desa- 
fios que o gestor enfrenta, não só nos 'nanosegundos dos anos 90' (Peters, 1992), mas desde que a gestão emergiu como disciplina (Chandler, 1962; Galbraith, 1967). Desde essa altura que duas correntes antagónicas têm concorrido para responder a estas questões, provocando um aceso debate entre quem as estuda, e um sério dilema a quem tem que lhes responder na vida prática. $O$ pouco que, comparativamente, há escrito sobre em que consiste, de facto, o trabalho do gestor, não nos permite escolher o vencedor deste combate. Não podemos também dizer que estamos perante um empate. Quem exerce a gestão, e quem a estuda no terreno, sabe que a realidade interna e externa das organizações não é, nem nunca foi, para utilizar a linguagem de Fonseca (2000), um relógio newtoniano. No entanto as paisagens fractais são também uma metáfora que foge à compreensão daquilo que é a média de quem habita as organizações, além de estar ainda pouco legitimada (apesar de avanços recentes [e.g. Anderson, 1999]) e por isso ser por ora imprópria para consumo de accionistas e banqueiros. De facto, regras e estruturas são um lugar comum mesmo nas organizações cujos resultados nos fazem exclamar UAU! (Peters, 1994), mas o que também é lugar comum nessas organizações são pessoas que dentro (e não apesar) dessa formalização conseguem, em conjunto, feitos extraordinários.

O nosso modelo de síntese entre a tese 'moderna' e a antítese 'tradicional' também não descreve tudo o que faz um gestor, mas tal como a improvisação em jazz, não pode ser considerado apenas um modelo normativo. Isto é fácil de entender se nos permitirmos um último exercício de dialéctica: o modelo que apresentamos é uma descrição normativa.

Pelas suas características, o modelo reveste-se de um conjunto de potencialidades teóricas e aplicadas que parecem merecedoras de ser expandidas. refinadas e testadas. Uma gestão para o séc.XXI, capaz de integrar paradoxos, de resolver dilemas, de descobrir novos conceitos, poderá, enfim, passar pelo uso da dialéctica como forma de criação de conhecimento novo sobre as 146 organizações. 


\section{REFERÊNCIAS}

ABRAHAMSON, E. (1991) Managenal fads and fashions:The diffusion and rejection of innovations. Academy of Management Review, 16 (3), 586-612.

AMABILE,T. (1998) How to kill creativity. Harvard Business Review, 76 (4), $77-87$.

ANDERSON, P. (1999) Complexity theory and organization science. Orgonizotion Science, 10 (3). $216-232$.

ANDREWS, K R (1995) The concept of corporate strategy. In H. Mintzberg, J. B. Quinn \& S Ghoshal (Eds.), The strategy process: European edition (pp. 55-64). Hertfordshire, UK: Pren. tice-Hall.

ARGYRIS, C. (1985) Strategy, change and defensive routines. New York: Pitman.

BAKER, W. E. (1994) Networking smart: How to build relationships for personal and organizational success. New York: McGraw-Hill.

BARNARD. C. (1938) The functions of the executive. Cambridge, MA: Harvard University Printing Office.

BARRETT, F. (1998) Creativity and improvisation in jazz and organizations: Implications for organizational learning. Organizotion science, 9 (5), 605-622

BASS, B. \& STOGDILL. R (1990) Bass and Stogdill's handbook of leodership. New York. Free Press. BASTIEN, D.T. \& HOSTAGER.T. J. (1988) Jazz as a process of organizational innovation. Communication Research, 15 (5), 582-602.

BERLINER. P. (1994) Thinking in jazz. Chicago: University of Chicago Press.

BETTIS, R. A. \& HITT, M. A. (1995) The new competitive landscape. Strategic Management Journal, 16,7.19.

BOHM, D. (1996) On dialogue. New York: Routledge.

BROWN. S. L. \& EISENHARDT, K. M. (1997) The art of continuous change: Linking complexity theory and time-paced evolution in relentlessly shifting organizations. Administrotive Science Quarterly, 42. 1-34.

BROWN, S. L. \& EISENHARDT, K. M. (1997) Competing on the edge. Boston, MA: Harvard Business School Press.

BYHAM,W. \& COX, J. (1998) Zopp! The lightning of empowerment. New York: Fawcett

CHANDLER, A. (1962) Strategy and structure: Chapters in the history of the industrial enterprise. Cambridge. MA: MIT Press.

COLLINS, J. \& PORRAS, J. (1997) Bult to last Successful habits of visionary componies. New York: Harper Business.

COOPER, R. (1994) Third generation new product processes. Journal of Product Innovation Management, 11, 3-14.

CRAIG, A. \& HART, S. (1992) Where now in new product development research. European Journal of Marketing. 26 (11). 1.49.

CROSSAN, M. \& SORRENTI. M. (1997) Making sense of improvisation. Advances in Strategic Management, 14, 155-180.

CUNHA, J.V. \& CUNHA, M.P. (2000). Organização: Tese, antitese, sintese. In M.P. Cunha (Ed.). Teona organizacional: Perspectivas e prospectivas, Lisboa: Dom Qurxote.

CUNHA, J.V., CUNHA, M.P. \& KAMOCHE, K. (1999. October) Minimal networks: A contribution to the deconstruction of organizations. Presented at the Strategic Management Society Con. ference, Berlin, Germany. 
CUNHA, M.P., CUNHA, J.V. \& CORREIA, M.F. (1999, July) Improvisational scenario planning: Alig. ning theories for better proctices for organizations in a changing world. 15th EGOS Colloquium, Sub-theme 6 improvisation and creativity in organizations, Warwick. England.

D'AVENI, R (1994) Hypercompetition. New York; Free Press.

DEBONO, E. (1986) Six thinking hats. New York Little Brown \& Co.

DEVRIES, K. \& MILLER, D. (1984) The neurotic organization. San Francisco: Jossey Bass

DRUCKER. P. F. (1993) Inovation and entrepreneurship (Revised ed.). New York: Harper Business. DRUCKER, P.F. (1994) Post-copitolist society. New York: Harper Business.

EISENBERG. E. M. (1990) Jamming: Transcendence trough organizing. Communication Research. 17 (2). 139-164.

EISENHARDT. K. M. \& TABRIZI, B. N. (1995) Accelerating adaptive procésses: Product innovation in the global computer industry. Administrotive Science Quarterly. 40. 84-110.

EMERY, F. \& TRIST, E. (1965) The causal texture of organizational environments. Human Relations, 26 (2), $21-32$.

FAYOL. H. (1949) General and industrial manogement. New York: Pitman.

FOLLETT, MARY P. (1940b) The giving of orders. in H. C. Metcalf \& L. Urwick (eds.). Dynamic administration: The collected popers of Mary Parker Follett (pp. 50-70) New York Harper \& Brothers Publishers.

FONSECA, ). (2000) Relógios mecânicos ou paisagens fractais. In M.P. Cunha (Ed.), Teoria organizocionat: Perspectivas e prospectivas. Lisboa: Dom Quixote.

FORRESTER. J. (1965) A new corporate design. Industrial Management Review, 7 (1). 5-17.

FRITZ, R (1989) The path of least resistance: Learning to become the creative force in your life ( $2^{\text {nd }}$ ed.) . New York: Fawcett Columbine.

FUKUYAMA, F. (1995) Confiança: Valores sociais e prosperidade. Lisboa: Gradiva

GALBRAITH, J.K. (1967) The new industrial stote. Boston: Houghton-Mifflin.

GREINER, L (1972) Evolution and revolution as organizations as organizations grow. Horvard Business Review 50 (4), 83-92.

GARDNER, W. \& ROGOFF, B. (1990) Children's deliberateness of planning according to task circumstances. Developmentol Psychology. 26 (3), 480-487

GREENLEAF, R. (1977) Servant leadership. New York Paulisi Press.

HACKMAN, J.R \& OLDHAM, G.R (1980) Work redesign. Reading, MA:Addison-Wesley.

HALAL,W., GERANMAYEH,A.\& POURDEHNAD. J. (1993) Intemal markets: Bringing the power of free enterprise inside your organization. New York Wiley.

HAMEL, G. \& PRAHALAD, C.K. (1994). Competing for the future. Boston: Harvard Business School Press.

HANDY, C. (1976) Understanding organizations. London: Penguin Books.

148 HANDY, C. (1990) The age of unreason. Cambridge, MA: Harvard Business School Press.

HARRISON, M. E. (1987) Diagnosing organizations: Methods, models and processes. Newbury Park, CA: Sage.

HARVEY,J. (1996) The Abilene paradox and other meditations on management. San Francisco: Jossey-Bass.

HAYEK, F. (1988) The fatal conceit The errors of socialism. Chicago: Chicago University Press.

HEDBERG, B. \& HOLMQVIST. M. (1999, October) Virtually knowledgeable: How imaginary organizations create and manage knowledge. Presented at the Strategic Management Society Conference, Berlin. Germany 
IMAI, M. (1989) Kaizen. New York McGraw-Hill.

JANIS, I. (1971) Groupthink. Psychology Today, November, 271-279.

JURAN, J. (1988) Juran's Quality Control Handbook. New York. McGraw-Hill.

KAMOCHE, K. \& CUNHA, M.P. (2000). From jazz improvisotion to product innovation. Não publicado.

KATZENBACH. J. \& SMITH, D. (1994) The wisdom of teams: Creating the high performance organization. New York: Harper Business.

KAUFFMAN, S. A. 1995. Escaping the red queen effect. The McKinsey Quarterly, 1: 119-129.

KOHLI, A.K. \& JAWORSKI, B.J. (1990) Market orientation: The construct, research propositions. and managerial implications. Journal of Marketing, 54, April, I. 18.

KOTLER, P. (1992) Marketing management Strategy, process and implementation. Hertfordshire, UK: Prentice-Hall.

LAWRENCE. P. R \& LORSCH. J.W. (1967) Organization and environment. Cambridge, MA: Harvard University Press.

LEVY. S. (1995) Insanely great: The life and times of the Macintosh, the computer that changed everything. New York: Penguin.

MASLOW, A. (1970) Motivation and personality. New York Harper Row.

MCGREGOR, D. (1960) The human side of enterprise. New York: McGraw-Hill.

MCCLELLAND, D. (1961) The achieving society. New York Van Nostrand.

MICKLETHWAIT, J. \& WOOLDRIDGE, A. (1996) The witch doctors: What the management gurus are saying, why it matters and how to make sense of it. London:William Hennemann.

MINTZBERG, H. (1994) Rounding out the manager's job. Sloan Management Review. Fall, I 1-26.

MINTZBERG, H. (1995) Five P's for strategy. In H. Mintzberg, J. B. Quinn \& S. Ghoshal (Eds.), The strategy process: European edition (pp. 13-21). Hertfordshire, UK: Prentice-Hall.

MOORMAN, C. \& MINER. A. S. (1998) The convergence of planning and execution: Improvisation in new product development joumal of Marketing, 62, 1-20.

NELSON, B. \& ECONOMY, P. (1996) Managing for dummies. Foster City, CA: IDG Books.

NONAKA, I. (1991). The knowledge creating company. Harvard Business Review, 71 (3), 96-104.

PERROW. C. (1986) Complex organizotions (3rd ed.) New York Random House.

PETERS.T. J. (1987) Thriving on chaos. New York Alfred A. Knopf.

PETERS, T. J. (1992) Liberation management The necessary disorganization for the nanosecond nine ties. New York Alfred A. Knopf.

PETERS.T.J. (1994) The pursuit of wow! New York Vintage Books.

PETERS.T. J. (1995) Creating and maintaining excellence. In G. Kawasaki \& R Bolles (Eds.). Hindsights: The wisdom and breakthroughs of remarkable people (pp. 40-50). New York: Wamer Books.

PETERS.T. J. \& WATERMAN RH. (1982) in search of excellence. New York Harper \& Row.

PETTIGREW, A. \& WHIPP, R. (1993) Understanding the environment. In C. Mabey \& B. MayonWhite (Eds.). Managing change (pp. 5-19). London: Paul Chapman.

PFEFFER J. (1992) Understanding power in onganizations. Colfornio Manogement Review. Winter. 29-50

PICKEN, J. C. \& DESS, G. (1997) Out of (strategic) control. Organizational Dynamics, Summer, 35-48.

POOLE, M. \& VAN DE VEN, A. (1989) Using paradox to build management and organization theories. Academy of Management Review. 14, 562-578. 
PORTER. M. (1998) Competitive Advantoge. New York Free Press.

POWELL, W. (1990) Neither market nor hierarchy. Network forms of organization. In L L Cummings \& B. M. Staw (Eds.). Research in Organizational Behavior (pp. 295-336). Greenwich. CT: JAl Press.

ROBBINS, S. (1990) Organization theory: Structure, design and opplications. Englewood-Cliffs: Prentice-Hall.

ROMANELLI. E. \& TUSHMAN, M. (1994) Organizational transformation as punctuated equilibrium: An empirical test. Academy of Management joumal, 5, 1141-1166.

SEMLER, R (1995) Moverick. New York Wamer Books.

SENGE, P.M. (1990) The fifth discipline: The art and practice of the learning organization. London: Century Business.

STACEY. R. D. (1996) Complexity and creativity in orgonizations. San Francisco: Berrett-Koehler. STALK, G. (1988) Time: The next source for competitive advantage. Harvard Business Review, 66 (4). $31-41$.

TAYLOR, F. (1911) Scientific management. New York Harper and Row.

VAN DE VEN, A. \& POOLE, M. (1995) Explaining development and change in organizations. Academy of Manogement Review, 510-540.

WEICK. K. E. (1979) The social psychology of organizing (2nd ed.). New York McGraw-Hill.

WEICK. K. E. (1993) Organizational redesign as improvisation. In G. P. Huber \& W. H. Glick (Eds.), Organizational change and redesign: Ideas and insights for improving performance (pp. 346-379) New York: Oxford University Press.

WEICK, K. E. (1999) The aesthetic of imperfection in orchestras and organizations. Comportomento Organizocional e Gestōo, 5(1). 5-22. 
(Página deixada propositadamente em branco) 
Série

Investigação

Coimbra

Imprensa da Universidade

2000 